\title{
Study on the Growth and Age of Spinibarbus denliculatus denliculatus in Pearl River System
}

\author{
Guangjun Wang, Deguang Yu, Jun Xie, Haiying Wang, Ermeng Yu, Wangbao Gong \& Lihua Tang \\ Pearl River Fishery Research Institute, Chinese Academic of Fishery Science \\ Guangzhou 510380, China \\ Tel: 86-20-8161-6178Ｅ-mail:wgj5810@163.com
}

This paper was supported by State Synthesis and Analysis Funds of China (No. (2007DKA31800-03-06).

\begin{abstract}
Study on the growth characteristics of Spinibarbus denticulatus denticulatus Oshima were carried out based on the specimens collected from Xijiang valley and Beijiang valley of the Pearl River system. The results show that the annual-ring feature belongs to the loose-close and cut pattern. The new annual-ring is formed during the period from April to June. The relationship between body length and weight of $S$. d. denticulatus in Xijiang valley and Beijiang valley can be expressed by the power function equations: $W_{X}=2.4984 \times 10^{-2} L^{2.9996}(\mathrm{r}=0.9561)$ and $W_{B}=1.3733 \times 10^{-2} L^{2.8159}(\mathrm{r}=0.9253)$ respectively. Based on the analysis of the growth stage, the female $S$. $d$. denticulatus gets mature at the age of five years old. The male one gets mature at the age of three years old. The breeding season of $S$. $d$. denticulatus is from April to June.
\end{abstract}

Keywords: Spinibarbus denticulatus denticulatus, Age, Growth

\section{Introduction}

Spinibarbus denticulatus denticulatus Oshima, also being called bamboo caldwelli or bamboo carp, is a kind of common commercial fish in the Pearl River system (Wu, 1977; Zhu, 1989; Yang \& Chen, 1995; Dan, 2000). It has become the main species cultured in rivers, reservoirs and ponds for its rapid growth, big size, exquisite meat and fresh flavor. In nature, $S . d$. denticulatus mainly distributes in Xijiang valley and Beijiang valley, which locate at the upreach and midreach of the Pearl River system (Zhang, 1998; Luo \& Xie, 2004; Tang, 2004; Zeng, etc, 2004). Generally speaking, the body weight of $S$. $d$. denticulatus is $1.0-1.5 \mathrm{~kg}$, with bigger individual reaches to $5-8 \mathrm{~kg}$ (Pearl River Fisheries Research Institute, 1991). Studies on $S$. d. denticulatus are reported as follows: Jiang Linyuan etc. had reported the relationship between age and growth under cultured condition (Jiang, etc, 2003); Yi Zusheng etc. had studied the embryonic development of Spinibarbus denticulatus denticulatus (Yi, etc, 2004). Xie Gang etc. had studied the relationship between embryonic development and water temperature, and salinity (Xie, etc, 2003). However, there was no systematic study on population biology under natural conditions. So in this paper, the age, growth and breeding of $S$. $d$. denticulatus in the Pearl River water system had been studied, which would provide scientific foundation on further development and protection of this fish resource.

\section{Materials and Methods}

\subsection{Materials}

S. $d$. denticulatus specimens were collected from Xijiang valley (From GuiPing of GuangXi to SanShui of GuangDong) and Beijiang valley (From Heyuan of Guangdong to SanShui of Guangdong) of the Pearl River water system between March in 2002 and December in 2004. 430 samples were captured with triple trammel nets. Scales were collected randomly from 200 samples and stored in numbering bags for age identification. 100 female and 30 male gonad samples were collected and immersed in 10\% formalin for further analysis.

\subsection{Methods}

Age identification: The lateral line scales were observed under dissection microscope to identify age. After amplifying 20 times by projector, the scale length $(R)$ and the radius of each annual rings $\left(R_{1}, R_{2}, R_{3} \ldots R n\right)$ was measured. Scale length was measured from the focus to the right angle of front zone of the scale. The radius of annual rings was measured from the focus to the interface of the front zone and the lateral zone.

Gonad histological observation: Gonads tissue was fixed in formalin, embedded in paraffin and stained by hematoxylin-eosin (HE) for pathological observation. 
The radiuses of eggs: measured under microscope by eyepiece micrometer.

Growth index $=\left(\log \mathrm{L}_{2}-\log \mathrm{L}_{1}\right) \times \mathrm{L}_{1} / 0.4343\left(\mathrm{t}_{2}-\mathrm{t}_{1}\right),\left(\mathrm{L}_{1}\right.$ and $\mathrm{L}_{2}$ are body lengths at two adjacent time $\mathrm{t}_{1}$ and $\left.\mathrm{t}_{2}\right)$;

Growth rate of scale edge $(\alpha)=\left(R-R_{n}\right) /\left(R_{n}-R_{n-1}\right) \times 100,\left(R_{n}\right.$ and $R_{n-1}$ are the radii of the last annual rings and penultimate annual rings).

\section{Results}

\subsection{Age Identification}

Morphological characteristics of scales: The scale of $S$. d. denticulatus was hexagonal, middle to big cycloid. The entire scale could be divided into front zone, back zone and lateral zone. Anterior parazona was wider than hinder parazona, but hinder parazona was longer than anterior parazona, which accounted for $2 / 3$ of the scale radii. Radiating furrow was not vertical with scale edge. Ring tablets were concentric circles and gradually form growth bands annually. Ring pattern in postzone scale turned to irregular granular protuberances.

Characteristics of annual rings: The growth of fish was affected by environment which change rhythmically, these phenomena reflected in scales, otoliths and other hard tissue. Fish grew faster in summer, so scales formed loose broad-bands. While fish grew slower in winter, the scales formed dense narrow-bands. The broad-bands and narrow-bands formed annual rings. The annual rings of $S$. $d$. denticulatus belongs to the loose-close and cut pattern. Generally speaking, ring tablets showed as loose-close structure before sexual maturity and sometimes the accretion of parazona and ring tablets were natural continuation of ring tablets from previous year. The difference was that newborn part dispersed toward the edge sparsely. However, annual rings showed as cut structure after sexual maturity and ring tablets often became disorder. Loose-close and cut structure appeared at the same annual ring. In the cut area, the inner edge showed as dense ring and the outer edge showed as loose ring. These phenomena occurred obviously in the postzone - parazona interface.

The subaltern ring occurred non-periodically and incompletely. They only appeared in partial prozone and lateral zone of scales and they were not commonly seen in elderly fish (over 5 years). Not all scales had subaltern ring in the same fish, so it was easy to distinguish.

\subsection{Population Composition}

Age composition: In Xijiang valley, $S$. d. denticulatus was mainly at the age of $0-2$, which occupied $73.67 \%$ of the 376 samples, while fish at the age of 3-5, 6-10 years respectively occupied $19.14 \%$ and $6.64 \%$, and fish of over 11 years occupied only $0.53 \%$.

Body length composition: The body lengths of 376 specimens were statistically classified. Most of the body lengths were between $11.5 \mathrm{~cm}$ and $29.5 \mathrm{~cm}$, which accounted for $63.30 \%$. Body length between $29.5 \mathrm{~cm}$ and $38.5 \mathrm{~cm}$ accounted for $13.83 \%$. The body length of the biggest male and female was $59.5 \mathrm{~cm}$ and $69 \mathrm{~cm}$, and the weight was $5250 \mathrm{~g}$ and $8250 \mathrm{~g}$, respectively.

In Beijiang valley, $S . d$. denticulatus were mainly at the age of $0-3$, which accounted for $66.67 \%$ of the 54 samples. Among which, the fish at the age of 2 were the majority, which accounted for $25.93 \%$ of the total.

\subsection{The Annual Ring Forming Period}

The growth rate of scale edge $\alpha=(R-R n) /(R n-R n-1) \times 100$ in Hass's method was used to calculate the change of average value of $\alpha$ in every age group(Hass \& Reckslek, 1995). When the new annual ring was forming, the average value of $\alpha$ was small. When the average value of $\alpha$ was increasing, it meant the new annual ring was going to form(Zhang, etc, 1981). According to annual change of $\alpha$ of $S$. d. denticulatus in Xijiang valley, the annual ring formed only once in a year, and new annual ring appeared mainly from April to June. This was proved by the captured $S$. d. denticulatus specimens during April to May, which just formed new annual ring. Growth rate of scale edge was inconsistent through a year. From December to next March, $\alpha$ value was relatively stable, that is to say the scale grew slowly in winter and spring. From July to November, $\alpha$ value increased gradually, which means scale edge grows rapidly in summer and autumn. The annual change of scale growth reflected the seasonal growth of $S$. $d$. denticulatus in Xijiang valley to some extent: it grew rapidly in summer and autumn, and slowly in winter and spring(Table 1).

According to gonadal histological study, S. d. denticulatus spawn between April and June, which coincided with the annual ring forming period. So, the annual ring of $S . d$. denticulatus formed only once in a year.

\subsection{The Relationship Between Body Length and Body Weight of S. d. denticulatus}

Body length and body weight were two correlated variables of animal growth. The result showed that the relationship between body length and weight of $S$. $d$. denticulatus in Xijiang and Beijiang valley was power 
functional and could be expressed with the formula of $W=a L^{b}$ (Figs. 1 and 2). According to the body length and weight value of all 430 specimens, formulas were got by Linear Regression method: $W_{X}=2.4984 \times 10^{-2} L^{2.9996}(\mathrm{r}=0.9561, p<0.01)$ for Xijiang valley and $W_{B}=1.3733 \times 10^{-2} L^{2.8159}(\mathrm{r}=0.9253, p<0.01)$ for Beijiang valley.

\subsection{Growth Stage Analysis}

From each age group including male and female in Xijiang and Beijiang valley, body length increased most rapidly in the first year and then the second year. With age increasing, annual growth rate of body length tended declining. On the contrary, body weight gain was the smallest in the first year, in the second year it began to increase. Annual growth rate of weight increased gradually with age increasing, but different age had different increasing amount. The 4-5 age groups had the largest increasing amount. Male and female $S$. $d$. denticulatus had no difference in growth when they were at the age of one to five years old, but over five years, female $S . d$. denticulatus had larger increasing amount in body length and weight than male one (Table 2).

Relative growth rates and growth index were used to divide growth stage, which could express growth features objectively. According to the study on gonadal histology, the female $S$. $d$. denticulatus in Xijiang valley got matured at the age of five years old. The $S$. $d$. denticulatus younger than five or four years was juvenile, whose gonadals was not mature or just primarily matured, they still grown quickly. Relative growth rates and growth index of body length and weight were the largest at that time. At the age of five to ten, the fish became adult and grew stable. Most food consumed for gonadal development and fat accumulation, so relative growth rates and growth index of body length and weight decreased gradually (Table 3).

S. d. denticulatus in Beijiang valley had the most rapid growth at the age of one to three, the relative growth rates and growth index were higher. When they were over four years, they grew slower, and the relative growth rates and growth index decreased.

\subsection{Breeding}

Beside of visual inspection, histological slices were mainly used to distinguish gonadal development stage (Shanghai Fisheries University, 1979; Su, 1995). Domestic scholars often divided the gonadal development stage into six phases. They were as follows:

Phase I : Ovary was linar, white and transparent. Under histological observation, the oocytes were polygonic and arranged closely. The nucleus occupied most part of the cells. Male or female couldn't be distinguished with naked eyes.

Phase II: The breadth of ovaries increased and back-end were larger, with showing itself light incarnadine. Oocytes enlarged, arranged and ranged closely. Nucleus located at the center of the cells and nucleoli manifolded along the edge. Oocytes in ovary were in small-growth period. The increase of protoplasm led to the small increase of volume of cells. The diameter of oocyte was between $37.50 \mu \mathrm{m}$ and $159.84 \mu \mathrm{m}$.

Phase III: Ovary expanded obviously because of the rapid development of oocytes. Cells were cylinder, with bright yellow. The width of ovary was $1.2 \mathrm{~cm}$ and the length was about $7 \mathrm{~cm}$. Eggs could be seen with naked eyes, with diameters between $83.25 \mu \mathrm{m}$ and $1731.60 \mu \mathrm{m}$. Oocytes had plenty yolk with nucleus in the center. The number of nucleoli increasing, two layer of follicular membrane and two or three liquid vacuoles appeared.

Phase IV: Ovary developed timidly, with the orange appearance. The eggs were bigger, with the diameter from $1393.00 \mu \mathrm{m}$ to $1798.20 \mu \mathrm{m}$. Yolk appeared in oocytes and protoplasm was displaced to the area around nucleus and near inner edge of cell membrane. Vacuoles also were pushed to the edge of cells.

Phase V: Ovarys were orange, tumid and bursiform. Eggs were big and there were free mature ova in ovarys. Matured ova were golden, spherical and transparent. The diameter of ova before absorbing water was between $2875.0 \mu \mathrm{m}$ and $3122.0 \mu \mathrm{m}$. The ova were buoyant.

Phase VI: Ovary diminished greatly and its tissues became soft. Surface vessels were filled with blood. Main remainder in ovary was oocyte at phase II and follicular membrane which had discharged ova. Oocyte which had not discharged would be digested and absorbed soon.

The development of the spermary was simultaneous with that of ovary, which also be divided into six phases.

Phase I : Gonad was undeveloped, linear and clung to the celarium. Male or female could not be distinguished with naked eyes. Spermatogonia distributed dispersedly could be seen by histological observation.

Phase II : Testis was linear, semiopaque and vessels was not obvious. The number of spermatogonia increased and arranged bunchly histological observation. 
Phase III: Spermary was columnar. There were no sperm extruded when abdomen was pressed. Primary spermatocytes could be seen by histological observation.

Phase IV: Spermary was opalescent and vessels distributed on the surface. Milky sperm could be extruded when abdomen was pressed at late stage. Primary spermatocytes, secondary spermatocytes and sperms could be seen by histological observation.

Phase V: The spermatogenic cysts were full of sperms. Abundant milky sperm could be extruded from cloaca when abdomen was lightly pressed or head was lifted.

Phase VI: Spermary diminished greatly in volume and the gonadal tissues were soft. Main remainder in spermary was some spermatogonia, primary spermatocytes and connective tissues. Testis recurred to phase III and then developed again.

100 ovarys were observed. Among which, $68 \%$ were at phase II , and all were over four years' age. $17 \%$ were at phase III and IV, and they all were five or over years old. Phase III and IV were the period that yolk began to deposite and accumulate, during which ova tended to mature, which showed that female $S$. $d$. denticulatus got mature at the age of five. At the same time, 30 testes were observed, there was no testis got mature at the age of no less than three years old. So the male $S$. d. denticulatus got mature should be at the age of three.

\section{Conclusion and Discussion}

According to the captured specimens of $S$. $d$. denticulatus, female fish got mature when they were over five years old. According to the report from Jiang Linyuan etc, female $S$. $d$. denticulatus got mature at the age of 4-5 under culture condition (Jiang, etc, 2003). These phenomena may be caused by the different entironment of culture and natural condition. S. d. denticulatus cultured artificially are fed with compound feed, the nutrients was abundant, so the gonad developed earlier. In this study, the mature samples may not enough, whether the sexual mature age is accurate or not need further studies. The $S$. $d$. denticulatus specimens in the study had large age span, this phenomenon reflected their sexual mature age was comparatively late. At the same time, it was showed that the breeding season of $S$. $d$. denticulatus was from April to June in this study, but Yi Zusheng etc had reported that the breeding season of $S$. $d$. denticulatus was from June to September under cultured condition. This may be caused by different rearing entironment ${ }^{[11]}$.

$0-2$ years old $S$. $d$. denticulatus in Xijiang valley occupied $73.67 \%$ of the total specimens, and $0-3$ years old $S$. $d$. denticulatus in Beiijiang valley occupied $66.67 \%$ of the total specimens, which indicated that juvenile $S$. $d$. denticulatus were captured excessively in Pearl River system. However, fishing target should be the populations with most of them got mature. Liao Fuchu reported that random enhancement of ships and nets, the use of illegal fishing appliance and illegal fishing during forbidden fishing period were the main reason causes leading to the decline of fisheries resources in Dongting Lake(Liao, etc, 2002). Presently, the number of $S$. d. denticulatus in Pearl River system reduced sharply, the relevant administration departments should promulgate corresponding rules, delimitting the fishing-forbidding areas and periods as soon as possible. Fishing should be restricted especially when fish were in spawning and propagating seasons. Only in this way, the $S$. d. denticulatus fishery resources could be protected and utilized reasonably, and achieved sustainable development.

\section{References}

Dan X H. (2000). Chinese zoography of Cypriniformes (second volume). Science press, Beijing, 130pp. (In Chinese).

Hass R E, Reckslek W C. (1995). Age verification of winter flounder in Narragansett Bay. Trans Amer Fish Soc, 124:103-111.

Jiang L Y, Yu X L, Chen F Y, etc. (2003). The Age and Growth of Spinibarbus denticulatus denticulatus under culture condition. Journal of Zhanjiang marine university, 23(4):6-13. (In Chinese).

Liao F C, He W, Huang X R, etc. (2002). Situation and variation of fisheries resources in Dongting Lake. Journal of hydrobiology, 26(6):623-627. (In Chinese).

Luo W K and Xie Z Y. (2004). Experiment on Spinibarbus denticulatus denticulatus cultured in reservoir net cages. Guangxi fisheries science and technology, 2:14-15. (In Chinese)

Pearl River Fisheries Research Institute, Chinese Academy of Fisher Sciences. (1991). Guangdong ichthyography of freshwater fishes. Press of science and technology of Guangdong. Guangzhou, 141-143. (In Chinese).

Shanghai Fisheries University. (1979). Histology and Embryology. Agriculture press, Beijing, 152-161. (In 
Chinese).

Su J X. (1995). Ichthyology and mariculture. Agriculture press, Beijing, 323pp. (In Chinese).

Tang Z H. (2004). Primary experiment on Spinibarbus denticulatus denticulatus cultured in ponds. Henan fisheries, 2:23-24. (In Chinese).

Wu W X. (1977). Chinese ichthyography of cyprinidae (second volume). Science press, Beijing, 97pp. (In Chinese).

Xie G, Chen K C, Hu Y C, etc. (2003). The relationship among, water temperature, salinity and embryonic development of Spinibarbus denticulatus denticulatus. Journal of Dalian fisheries college, 18(2): 95-98. (In Chinese).

Yang J X and Chen Y R. (1995). Study on species differentiation of Spinibarbus genus. Journals of Zhangjiang fisheries college, 15(1):1-5. (In Chinese).

Yi Z S, Chen X L, Wang C, etc. (2004). Study on embryonic development of Spinibarbus denticulatus denticulatus. Chinese fisheries science, 11(1):65-69. (In Chinese).

Zeng Q X, Zhu E H, Zhang J H. (2004). Experiment on Spinibarbus denticulatus denticulatus mainly cultured in ponds. Jiangxi fisheries science and technology, 2:36-39. (In Chinese).

Zhang Q Y, Li F Z, Du J R. (1981). Study on the Age and Growth of Mugil cephalus in Xinlin Bay of Xiamen. Fisheries journal, 5(2):121-131. (In Chinese).

Zhang S B. (1998). Experiment on Spinibarbus denticulatus denticulatus cultured with high density in small net cages. Fisheries modernization, 6:6-7. (In Chinese).

Zhu X L. (1989). Ichthyography in Yunnan Province (first volume). Science press, Beijing, 153pp. (In Chinese).

Table 1. The marginal increment ratio of scale of $S$. $d$. denticulatus

\begin{tabular}{|c|c|c|c|c|c|c|c|c|c|c|c|c|}
\hline Month & 1 & 2 & 3 & 4 & 5 & 6 & 7 & 8 & 9 & 10 & 11 & 12 \\
\hline Average value of $\alpha$ & 6.36 & 7.38 & 8.00 & 4.38 & 2.30 & 3.60 & 7.92 & 8.79 & 7.74 & 8.97 & 10.18 & 9.27 \\
\hline Number of spcimens & 3 & 5 & 7 & 12 & 7 & 4 & 6 & 11 & 11 & 7 & 4 & 22 \\
\hline
\end{tabular}


Table 2. Measure and annual increment of different ages of $S . d$. denticulatus

\begin{tabular}{|c|c|c|c|c|c|c|c|}
\hline Sex & & Age & Number & $\begin{array}{l}\text { Measure body } \\
\text { length } / \mathrm{cm}\end{array}$ & $\begin{array}{c}\text { Annual } \\
\text { increment } / \mathrm{cm}\end{array}$ & $\begin{array}{l}\text { Measure body } \\
\text { weight/g }\end{array}$ & $\begin{array}{c}\text { Annual } \\
\text { increment } \\
/ \mathrm{g}\end{array}$ \\
\hline & & 1 & 57 & $20.47 \pm 2.93$ & 20.47 & $228.46 \pm 94.51$ & 228.46 \\
\hline & & 2 & 86 & $27.52 \pm 3.36$ & 7.05 & $541.54 \pm 183.82$ & 313.08 \\
\hline & & 3 & 15 & $34.25 \pm 3.33$ & 6.73 & $946.53 \pm 272.13$ & 404.99 \\
\hline & & 4 & 11 & $40.02 \pm 2.21$ & 5.77 & $1586.21 \pm 268.22$ & 639.68 \\
\hline & t & 5 & 13 & $46.76 \pm 2.01$ & 6.74 & $2510.32 \pm 412.61$ & 924.11 \\
\hline & & 6 & 7 & $49.98 \pm 2.23$ & 3.22 & $2974.53 \pm 404.32$ & 464.21 \\
\hline & & 7 & 9 & $54.32 \pm 5.78$ & 4.34 & $4113.67 \pm 1089.22$ & 1139.14 \\
\hline Xijiang & & $\geq 8$ & 3 & $55.46 \pm 10.42$ & 1.14 & $4422.78 \pm 2545.36$ & 309.11 \\
\hline Valley & & 1 & 42 & $19.90 \pm 2.88$ & 19.90 & $209.09 \pm 82.04$ & 209.09 \\
\hline & & 2 & 92 & $27.87 \pm 3.29$ & 7.97 & $547.05 \pm 187.23$ & 337.96 \\
\hline & & 3 & 14 & $33.40 \pm 3.58$ & 5.53 & $915.87 \pm 288.73$ & 368.82 \\
\hline & $\lambda$ & 4 & 13 & $40.60 \pm 2.55$ & 7.20 & $1540.63 \pm 364.11$ & 624.76 \\
\hline & 0 & 5 & 6 & $43.43 \pm 2.17$ & 2.80 & $2157.14 \pm 356.40$ & 616.51 \\
\hline & & 6 & 3 & $51.50 \pm 0.71$ & 8.07 & $3075.16 \pm 106.07$ & 917.86 \\
\hline & & 7 & 3 & $52.25 \pm 1.55$ & 0.75 & $3275.26 \pm 320.16$ & 200.10 \\
\hline & & $\geq 8$ & 2 & $53.00 \pm 6.89$ & 0.75 & $3900.26 \pm 1316.85$ & 625.00 \\
\hline & & 1 & 6 & $20.78 \pm 3.12$ & 20.78 & $245.36 \pm 94.69$ & 245.36 \\
\hline & & 2 & 9 & $28.45 \pm 2.96$ & 7.67 & $522.36 \pm 211.45$ & 277.00 \\
\hline & & 3 & 8 & $32.96 \pm 1.65$ & 4.51 & $934.67 \pm 270.50$ & 412.31 \\
\hline & q & 4 & 4 & $40.23 \pm 3.58$ & 7.27 & $1611.24 \pm 188.59$ & 676.57 \\
\hline & & 5 & 3 & $44.98 \pm 3.36$ & 4.75 & $2456.95 \pm 236.19$ & 845.61 \\
\hline & & 6 & 3 & $50.76 \pm 3.36$ & 5.78 & $2869.34 \pm 546.29$ & 412.39 \\
\hline & & 7 & 2 & $53.96 \pm 4.63$ & 3.20 & $4054.63 \pm 1523.63$ & 1185.29 \\
\hline Beiijiang & & $\geq 8$ & 2 & $54.87 \pm 7.22$ & 0.91 & $4411.03 \pm 653.45$ & 356.40 \\
\hline Valley & & 1 & 4 & $19.87 \pm 3.21$ & 19.87 & $212.46 \pm 78.46$ & 212.46 \\
\hline & & 2 & 5 & $26.55 \pm 3.12$ & 6.68 & $521.25 \pm 214.46$ & 308.79 \\
\hline & & 3 & 4 & $32.98 \pm 5.63$ & 6.43 & $877.68 \pm 301.27$ & 356.43 \\
\hline & & 4 & 2 & $37.65 \pm 3.39$ & 4.67 & $1312.49 \pm 386.41$ & 434.81 \\
\hline & o & 5 & 1 & 45.45 & 7.8 & 2284.17 & 971.68 \\
\hline & & 6 & & - & & - & \\
\hline & & 7 & 1 & 52.31 & & 3533.21 & \\
\hline & & $\geq 8$ & & - & & - & \\
\hline
\end{tabular}

“-”No fish specimen collected.

Table 3. Analysis of growth stage of S. d. denticulatus

\begin{tabular}{|c|c|c|c|c|c|c|}
\hline \multirow{2}{*}{ Age } & \multicolumn{3}{|c|}{ Xijiang valley } & \multicolumn{3}{c|}{ Beijiang valley } \\
\cline { 2 - 7 } & $\begin{array}{c}\text { Growth } \\
\text { index }\end{array}$ & $\begin{array}{c}\text { Body length } \\
\text { gain/\% }\end{array}$ & $\begin{array}{c}\text { Body weight } \\
\text { gain/\% }\end{array}$ & $\begin{array}{c}\text { Growth } \\
\text { index }\end{array}$ & $\begin{array}{c}\text { Body length } \\
\text { gain/\% }\end{array}$ & $\begin{array}{c}\text { Body weight } \\
\text { gain/\% }\end{array}$ \\
\hline $1^{+}$ & & & & & & \\
\hline $2^{+}$ & 6.18 & 35.62 & 140.42 & 6.09 & 34.52 & 132.44 \\
\hline $3^{+}$ & 5.56 & 22.38 & 74.22 & 5.82 & 23.45 & 75.14 \\
\hline $4^{+}$ & 6.00 & 19.50 & 69.80 & 5.26 & 16.68 & 69.85 \\
\hline $5^{+}$ & 5.06 & 13.41 & 51.94 & 6.49 & 17.71 & 58.23 \\
\hline $6^{+}$ & 4.52 & 10.40 & 25.29 & 3.78 & 7.83 & 34.58 \\
\hline $7^{+}$ & 2.40 & 4.88 & 17.58 & 3.21 & 7.09 & 18.33 \\
\hline $8^{+}$ & 1.85 & 3.56 & 11.79 & 1.21 & 2.27 & 7.92 \\
\hline
\end{tabular}




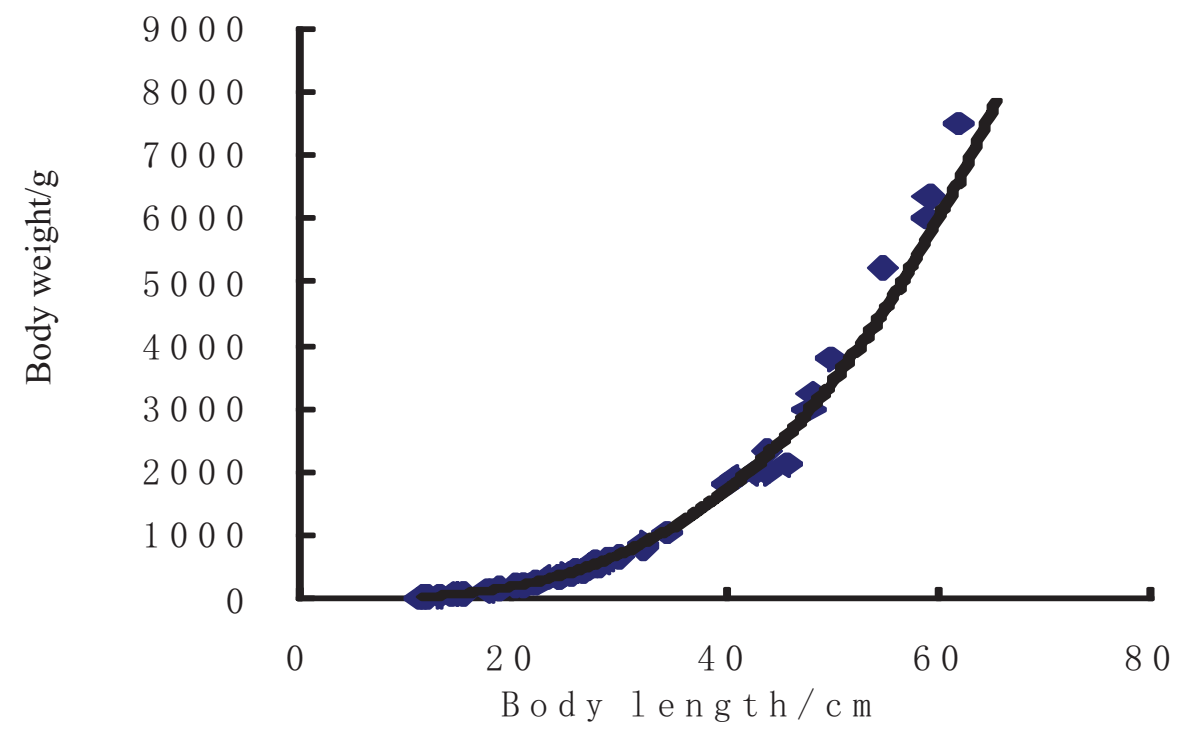

Figure 1. The relationship between body length and weight of $S . d$. denticulatus in Xijiang valley

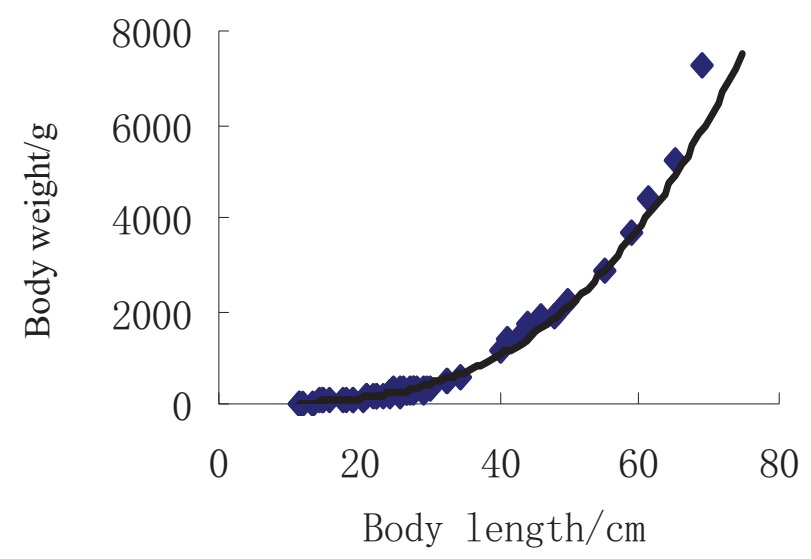

Figure 2. The relationship between body length and weight of $S$. d. denticulatus in Beijiang valley 